\title{
The Effects of Muslim Religious Beliefs on the Impact of Covid-19 of the Rural Citizens
}

\section{Shahid Nadeem ${ }^{1, *}$, Bilal Hummayoun Butt ${ }^{2}$ and Hassan Imran ${ }^{3}$}

\begin{abstract}
The impacts of COVID-19 outbreak on human being mental health issues have given indication for the alarming situation for sustaining a healthy lifestyle. The diverse significance of the disease surrounded by religious group of people, ontologically, as well show the ways to an assortment of fitting sensible actions in the face of dispersion a virus. Current study focuses on intellectualize and treasure the association between religious beliefs and the impact of COVID-19 among the rural population of Pakistan. Three hundred and forty adults of central Punjab comprising of three districts including Sargodha, Faisalabad and Khushab ( $N=340)$ from both genders were taken by using purposive sampling technique. Religious beliefs were measured using the religious belief scale and the impact of COVID-1 9 was measured using the impact of event scale as impact of event scale-Revised (IES-R). Results revealed that a negative association was found between religious beliefs and impact of Covid-19 outbreak. Study also explored the relationship between religious beliefs and dimension of the impact of Covid-19 including Intrusion, avoidance and Hyper-arousal. Further study found that religious beliefs predicted the impact of Covid-19 negatively. Due to strong Muslim religious beliefs, they believe that Covid-19, a disease is brought by the Almighty God, and it is the Almighty who can remove this pandemic. Study was completed in short span of two months. In future it is suggested that there is need to more work on other departments of different territories Punjab (Pk).
\end{abstract}

Keywords: Religion, COVID-19, Intrusion, Avoidance, Hyper-Arousal.

${ }^{1}$ Faculty of Managements Sciences Department, DHA Suffa University, Karachi, Sindh, Pakistan. Corresponding Author: snadeem9@hotmail.com ${ }^{2}$ Head Office, Defense Housing Authority (DHA), Lahore, Punjab, Pakistan.

${ }^{3}$ Department of Clinical Psychology, University of Lahore, Lahore, Punjab, Pakistan. 


\section{Introduction}

In December 2019, In China the Province "Wuhan Hubei”, a number of series of patients of pneumonia disease was reported of unidentified reason. Epidemiological findings were exposed within human beings, and later on the (WHO) specified it with Corona Virus Disease COVID19.

The disease is entrenched by corona virus and it can be distributed from one person to another person. Corona virus is already challenging in several countries all over the world. The significant reflection is usually on the local announcement. The Government of China broadcasted the conservatory of the spring event holiday for specific period, the educational departments, business departments, visiting parks, professional meetings, religious get-together are strictly prohibited due to COVID-19 (Sharma, 2021). Moreover, five million individuals have seemingly missed in Wuhan, a China City. In contrast with the viruses like SARS and the Ebola, COVID-19 is decidedly transmittable through the incubation time period. COVID-19 can be transferred during respiratory bead. As findings, on large scale disease of COVID-19 has been reasoned a Universal. During clinical surveillance, many patients of Pakistan urbanized the COVID-19 anxiety. COVID-19 anxiety as a kind of emotional stress which activate a series of physiological proceedings and cause reduces in immune system and psychological health as well (Mannan \& Akram, 2020).

The impacts of COVID-19 outbreak on human being mental health issues have given indication for the alarming situation for sustaining a healthy lifestyle. The COVID-19 outburst routed the people emotional responses psychological disorder such as tension, pressure, tenseness, etc. which produces direct effect to the psychological disorders such as the posttraumatic stress disorder, acute stress disorder, depression and suicidal attempts(Durkin \& Bhulla, 2020). It has been pointed that The Academician Zhong Nanshan the leader of the highlevel authorities' cluster, that psychological horror is much fearful than the disease.

The COVID-19 breakout may be the massive source of mental illness likewise stress, anxiety, depression and other related psychological issues and this Covid -19 is also source of overwhelming in people of Pakistan as the many cases have been reported that the people whose are confined at quarantine centers, have strongly wish to withdraw themselves from those centers. So many people are not willing to test themselves (Dam \& Mandal, 2020). The people those may have strong anxiety about this disease are the older people, the people already associating with chronic disease. The impact of Covid-19 influenced the people specially those who are working at Hospitals and the other mental health centers as well. It can be the massive impact of human life such as the changing of sleep pattern, eating pattern, mood instability, increase in substances using, and other mental health issues (Laires \& Nunes, 2021).

Religious beliefs in decade, the mental health researches in social studies have proved that there is some positive connection has been found among the religious beliefs and the mental health. The people who are strong committed with religious activities, foresees the less mental health issues (Moreira Almeida \& Koenig, 2006). The adults and even elders having strong 
religious beliefs, member of religious communities have the less anxiety and have strong hope for avoidance as they have strong spiritual connection between the well -being and social life. It is so because these bow their hands before God by praying and ultimately have the hope for the blessings (Mackenzie \& Lavizzo Mourey, 2000).

The biggest problem most religions face currently is the dilemma or burials being conducted. In Sri Lanka burials are not allowed to be conducted if the patient has suffered from COVID-19. This has affected the Muslim community the most as they have to see their loved ones being cremated without being buried. There is no doubt that faith and religious beliefs affect different aspects of human life the Covid-19 had a serious effect on all religious bodies across the world and were put in a situation never faced before (Razak \& Saleem, 2021). Every country should adhere to the WHO guidelines given for the purpose and adhere to it as I believe and after this situation calms down religious leaders need to interact and discuss to find a common solution that would prevent conflicts and issues.

The perceptions of wellbeing and illness have profound roots in religious beliefs with a resultant variety of performances, which must be continuously examined and contemplate, predominantly during a pandemic once individual performances may positively or negatively impression on ailment control (Sinha, Shahbaz \& Sengupta, 2018). Seeing how much religion can inspiration culture, it is imperative to be conscious of outdated thoughts that link religions with disease, subsequently these perceptions may disturb the retorts of some groupings of believers once in time of health catastrophe.

Thus, the participants in the religious activities, religious meetings, and communities lead to less mental disorder. Anxiety was also lowered for those who were involved in the religious activities and were committed with God for sustaining the better mental health. Moreover, the adults, those were attached with the religious activities frequently and having the high level of spiritual communities have the lowest degree of anxiety and in contrast those having less religious commitment increases the level of mental illness. The current study has tried to explore the association between the religious beliefs of an individual and impact of Covid-19 outbreak (Maselko \& Kubzansky, 2006).

\section{Literature Review}

The diverse significance of the disease surrounded by religious group of people, ontologically, as well show the ways to a assortment of fitting sensible actions in the face of dispersion a virus. Traditionally, spiritual group of people has a elongated view that repeatedly disagree with systematic viewpoint in accepting diseases, together with disease. Illness, for the illustration, the outcome about the profession of Satan, which is the particular immorality. The indispensable, one of the church's sovereigns, affirmed: It is enormous which manufactures deficiency, sterility, dishonesty's of the air, infection; they float disguised in obscures in the subordinate impression and are connected by the blood and enrage which the heathen tender to them. In the past history Philosopher, the most important untimely sovereign of the Church, he stated that all sickness of Christians the characterized to these terrible characters, primarily do they anguish clean described, even the not guilty, baby infant. 
With Pope Pius V's orders, every doctor is necessitated to be explained cogent doctors for the reason that 'weak spot of the body time and again happen due to peccadilloes.' Satan's approach and wickedness cause underprivileged healthiness. Restorative is done by constrain out the iniquity spirit from aperture to last tools such as sacred relics. Abundant donations flow to poles apart churches and monasteries, which are notorious to have unfastened ends that can nurse back to health. The church is not any more than a guardian of a Christian's quintessence but also a bodily guardian (Bisri, 2020).

The Church outlook that diseases, such as smallpox and cholera, additionally as God's chastisement, injections for wounded are fervently is in opposition to by the mainstream. The residence of a man who gave defense to the original different types of disease investigator, Boylston, was pelted with bullets. Mortification is poured out commencing the platforms to supporters of vaccination. But the particulars are so dependable with the inoculation that human being can carry on to live, and lacking the dose, they will pass away. So that the mixture was in conclusion accepted by the Church, smooth although the fighting was on no account completely smother (Gearhart, 2017).

A severe obstruction in the growth of scientific medicine is the negative response of dead body surgical procedure. St. Augustine stated to anatomists as 'butcher' and powerfully destined this put into practice. The universal terror is that wounding off a dead body will reason inconceivable revulsion on the daylight hours when all people are bring back to life. To this disagreement, the Church adjoins again, "the Church the peeling of blood. In 1770, a wonderful experience was monitories in more than a few regions of Europe. A comprehensive declaration was sent to the Royal Academy of Science, condition that hose down has turned into blood.

The clergy without delay saw this suggestion as God's annoyance (Wells, 2015). At what time a comparable phenomenon was seen in Sweden, a renowned environmentalist, Linnaeus, examined this observable fact conscientiously and exposed that the watering of water was grounds by a huge collection of little insect and make known that "the reddening of the hose down is not ordinary. In the past history is witness that church willingly maintain that comets are fireballs fearful by divinity who are irritated at an immorality humanity, cathedral campaigner demonstrates the proper assessment of comets by evaluate the God who fling a comet with a moderator who puts a completing sharp edge on the table on the bench flanked by self-power and the bad character in the court of law.

Other church groups criticize those who not willing to care regarding the caution of God and associate with their "calves wide open at a new barn door" (Giberson, 2012). Still as not on times as the 17th century astronomy lecturer were wedged up by their pledge to educate those comets are external breathing space bodies that whole the laws of physics. But essentially, science cannot be dammed. Halley, using Newton and Keppler's hypothesis, watched the course of a 'dangerous' comet and forecast that it would become visible accurately 77 years afterward. He calculates faithfully until the minutes when the comet would be see yet again at a confident point 
in the sky. This is unbreakable to judge. But 76 years later, when Halley and Newton died stretched ago, Halley's returned, vaguely as calculate (Panek, 2019).

\section{Background of the Study}

In 2019 Novel Corona virus (COVID 19) has develop into a contagion almost all over the place in the world and the pro-contra replied have come forward with spiritual group of people about the derivation and natural world of the COVID 19, and their collision on human being. A numeral of the associate of spiritual population observations about COVID 19 as a virus have been completed by human made disease that was deliberately generated as an organic bludgeon. So, there are outlook the virus COVID 19 as a disease that is living organism investigated and urbanized in the middle of modern labs, due to this reason, the lack of care by their researcher, later on then the virus increases out of bed in command of. Another hand the view of people about this disease as God's military to obliterate the evil human on this universe. But a lot of them see this virus as an ordinary disease that come into sight of course (Bisri, 2020) The assortment of views and approach among spiritual group of people unable to be alienated from their world view in sympathetic reality. Their viewpoints are shaped from end to end a long journey, strong conversation, and important communications with the variables of their learning, social life, civilization, financial system and spiritual thoughtful.

It is suggested that Muslim religious belief, in poles separately perspectives surrounded by devout population on the boulevard to truth, together with this COVID 19, then, boast propositions for the way they react to this virus. These, for instance, appears on or after four the Americans investigate in the United States in 2014. The United States knowledge in density in measles pressure collection, the majority since the removal of the virus in 2000. Revision suggested that Measles illness take place in unvaccinated persons (Kor, 2006). Group of people and individuals decide not to inoculate for quite a few reasons, first and foremost allege spiritual and theoretical thoughtfulness. Protestation based upon faith regularly center on bring into fool around of call a halt individual worst tissue used in the of virus rubella ingredient of the come together vaccine foodstuffs, and animal resultant gelatins used in vaccine manufacture. Objections in the middle of spiritual communities may as well not be faith-based, if at all possible, in some suitcases participation narrated to be short of safekeeping and effectiveness of the immunization result in keeping out (Kagan, 2001).

Therefore, based on the thorough literature review the researchers of this study have attempted to address the relationship between the religious beliefs and the impact of COVID-19. The following research hypotheses and theoretical framework were created:

H1: Muslim Religious believe have a positive effect of COVID-19 among the rural citizens.

H2: CIVID-19 having caused the psychological distress among the rural citizens.

H3: Religious beliefs have a positive connection with religious beliefs among the rural citizens.

Finally, the significance of this study can be seen as, COVID-19 threatens our common existence, and the response to this threat is a great unifying factor for all communities of faith. 
Spiritual cream of the crop occupies location of leadership in local group of people. They could engage in leisure a key role in assemble their individual group of people in the reply to the pandemic. Religious attitude and observances offer important resources for coping with the adverse effects of the pandemic. Covid-19 was an unpredicted occurrence for all factions of diverse religions and relationships, as well. Nonetheless it does not unkind that they do not have the involvement to transaction with it (Murenje \& Porter, 2020). For occurrence, Muslims were faced comparable contagion catastrophes in traditional times, and they have some detailed rules management such circumstances. Covid-19 had a serious effect on all religious bodies across the world and was put in a situation never faced before but this saw a rise on social media platforms which were now being used as a platform to continue to spread their individual messages to their communities (Altamirano, 2020).

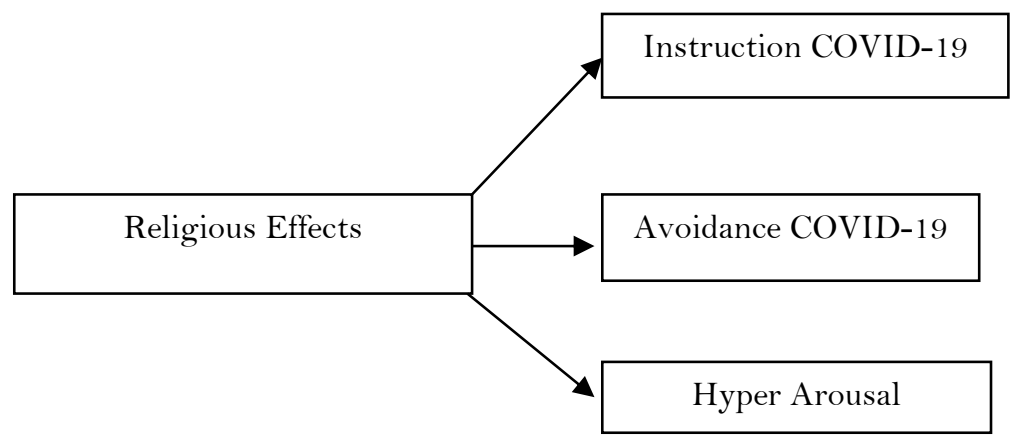

Figure 1: Theoretical Framework

\section{Research Methodology}

\subsection{Research Design}

Cross sectional, the study method is based on quantitative costumed with questionnaires for gathering of data for variables impact of COVID-19 and religious believe. In gratifying the object of this study, this experimental study explored the association among COVID-19 and religious believe among the rural Pakistani citizens.

\subsection{Sampling}

Population for the study was adults both male \& female in three districts of Punjab (Pakistan) as narrated earlier. The populaces of current study comprise the people who lived in rural areas of Sargodha, Faisalabad and Khushab and are there in situated in Pakistan. The study was based on disseminated self-managed questionnaires with the assistance of the interaction person, subsequent the purposive sampling method. The 1050 questionnaires were distributed and acknowledged back 850 questionnaires after the whispered sampling, of which 340 originate practical for data examination determination. The effective answer frequency was $80.95 \%$ and functioning questionnaire was $75.82 \%$, as well. 


\subsection{Sampling Techniques}

Sampling method was bases on non-probability (purposive sampling techniques), was tracked in the current study with purposive and convenient sampling methods were used. Respondents of this study designated on the substance of the accessibility and the eagerness for the involvement in the study.

\subsection{Apparatus or Measures}

For the measurement of the current study variables the development scale, for religious beliefs and Impact of Covid-19 were found reliable by measuring its reliability on Cronbach's alpha whereas its reliabilities for the scales were excellent 0.95 and 0.94 respectively. Five-point rating Likert scales were used.

Table 1: Cronbach's Alpha

\begin{tabular}{ccc}
\hline Scales & No. of Items & Alpha Reliability \\
\hline Impact of Covid-19 & 22 & 0.95 \\
Religious Beliefs & 14 & 0.094 \\
\hline
\end{tabular}

\subsubsection{Measurement of religious beliefs.}

Religious belief scale was developed a having 17-items with four confirmatory factors i.e., religious effect, divine, religious query and religious stress. The questionnaire was primarily designed for Taiwanese nurses; however, it can be applied to general population as well. All the 17 items are achieved on a 5-point Likert Scale from strongly disagree to strongly agree (1 to 5). The questionnaire was slightly modified to capture the Muslim religious beliefs.

\subsubsection{Measurement of impact of COVID-19.}

As the Covid-19 is worrisome event happening all over the world, this study used IES-R scale to measure the impact of Covid-19. IES-R Impact of Event Scale - Revised is a 22-item questionnaire rated on a Likert scale from o to 4. The IES-R was revised by Steven Christianson (2013) and a suitable instrument to quantity the individual answers to a precise shocking event. The scale was upgraded treating Covid-19 outbreak as a traumatic event. For the determination of examining the data of the existing study, Statistical Package for the Social Sciences (SPSS) was utilized to constitute the analysis technique of the collected data.

\subsection{Data Collection Procedure}

Data was collected in Pandemic 2nd Phase. The data collection via substantial of surveys of Likert scale by the plaintiffs during individual appointment of the investigator after authorization from the apprehension approves. Contributor of the study was requested to the make obtainable acquired consent. Contributors were acknowledged in the conclusion for philanthropic their evidence and time and also their collaboration. No recompense was paid to the contributors in this study, as all contributors were eager to contribute in the study. 


\subsection{Ethical Concerns}

All contribute in current study were intended, directions were pure to all sponsors of current study and was conversant the preceding for the concluding the survey the contributor was recognized the coincidental to valuation and the representation an familiar authorization from the prior for the contributing and the individuals who strength not command to get the dissection in the study they were requested for the recurring the survey and consequently it had no more obligations for this study. Society standards and norms were tracked.

\section{Results}

Finding shows that religious beliefs have significant negative correlation with the impact of Covid-19 and its dimensions. Table 2 also shows that Impact of Covid-19 have significant correlation with its dimensions i.e., intrusion, avoidance and hyper arousal.

Table 2: Correlation Matrix

\begin{tabular}{cccccccc}
\hline Variables & $\mathbf{1}$ & $\mathbf{2}$ & $\mathbf{3}$ & $\mathbf{4}$ & $\mathbf{5}$ & Mean & $\boldsymbol{S D}$ \\
\hline Religious Beliefs & - & $-0.94^{* * *}$ & $-0.95^{* * *}$ & $-0.83^{* * * *}$ & $-0.88^{* * *}$ & 60.81 & 14.02 \\
Impact of Covid-19 & & - & $-0.96^{* * *}$ & $-0.93^{* * * *}$ & $-0.93^{* * *}$ & 60.00 & 17.07 \\
Intrusion & & & - & $-0.83^{* * *}$ & $-0.86^{* * *}$ & 21.70 & 6.72 \\
Avoidance & & & & - & $-0.83^{* * *}$ & 22.53 & 6.83 \\
Hyper arousal & & & & & - & 16.17 & 4.13 \\
\hline
\end{tabular}

Note: $* * * p<.001$

Table No 3, a simple linear regression was calculated to predict the impact of Covid-19 on religious beliefs. Significant regression equation was found $[F(1,338)=2582, p<.001]$, with an $\mathrm{R} 2$ of 0.88 . The Impact of Covid-19 on participants significantly decreases by -1.14 for high religious beliefs.

Table 3: Regression Analysis

\begin{tabular}{cccccc}
\hline Variable & $\mathbf{B}$ & $\mathbf{9 5 \%} \mathbf{C I}$ & $\boldsymbol{\beta}$ & $\mathbf{t}$ & $\mathbf{P}$ \\
\hline Constant & 129.60 & {$[126.84,132.37]$} & - & 92.21 & .001 \\
Religious Beliefs & -1.14 & {$[-1.19,-1.10]$} & .94 & -50.82 & .001 \\
\hline
\end{tabular}

Note: $R^{2}$ adjusted $=0.88 C I=$ Confidence Interval for $\beta$

\section{Discussion and Conclusion}

The first objective of the study was to find the relationship/association between religious beliefs and impact of Covid-19 among the urban and rural citizens of Pakistan. Both Religious beliefs and Impact of Covid-19 were significantly negatively associated according to study results. Study also showed that Religious Beliefs and sub-variables of the impact of Covid-19 (Intrusion, avoidance and Hyper-arousal) were also significantly negatively correlated with each 
other. Additional, Regression analysis demonstrates that religious viewpoint considerably forecast the impact of Covid-19 among the rural citizens. The findings of the current study are in line with the previous literature (Pinker, 2021).

Empirically examine the relationship among religious beliefs, irrational estimation and undesirable's sentiments. They originate that mere connotation of a chain of undesirable events with robust religious belief induce less worry and sadness. They found that more religious beliefs tend to experience lower levels of emotional distress. They further explored those participants who believe in the clemency of the Enormous God tend to end to sanction less self-put down beliefs as self-put down beliefs are one of the proximal causes of the depression. Their study findings were very similar to this one. As Covid-19 outbreak is happened all over the world, it is a worry and saddening still. Current study strengthens the above finding that strong religious beliefs have a positive role in a stressing event.

In context of Pakistan, the results of this study can explain following things. Due to strong Muslim religious beliefs, Covid-19 outbreak has little interference in the rural life. Although people are aware of the Covid-19 outbreak through Media yet have strong Muslim religious beliefs. By thus, they have overcome their fear of the pandemic. Due to strong Muslim religious beliefs, they believe that Covid-19, a disease is brought by the Almighty God, and it is the Almighty who can remove this pandemic. It was seen that Pakistani rural population are less hyperactive aroused about Covid-19 due to their strong religious beliefs.

This experiential study inspected for investigation the impact of between religious beliefs and impact of Covid-19 among the urban and rural citizens of Pakistan. The current study has main impartial was to determine the association among the religious beliefs and impact of covid -19. Research design was based on correlation method; used in which data from the N340 defendants composed using a self-managed questionnaire from Pakistan. Purposive sampling technique was used for respondents and data was examined a regression statically analysis. The result is explained in three forms; Demographic information, descriptive analysis, and inferential analysis. Finding shows that religious beliefs have significant negative correlation with the impact of Covid-19 and its dimensions.

It is also shown in Table, that impact of Covid-19 has significant correlation with its dimensions i.e., intrusion, avoidance and hyper arousal. Current study strengthens the above finding that strong religious beliefs have a positive role in a stressing event. In context of Pakistan, the results of this study can explain following things. Due to strong Muslim religious beliefs, Covid-19 outbreak has little interference in the rural life. Although people are aware of the Covid-19 outbreak through Media yet have strong Muslim religious beliefs. They have overcome their fear of the pandemic. Due to strong Muslim religious beliefs, they believe that Covid-19, a disease is brought by the Almighty God, and it is the Almighty who can remove this pandemic. It was seen that Pakistani rural population are less hyperactive aroused about Covid19 due to their strong religious beliefs. 


\section{Study Limitations, Future Directions and Recommendations}

This study is based on a cross-sectional and the self-report measures were used. These are clear limitations so that in potential researchers could board on the longitudinal studies in order for the establishing the causal association. Additionally, to self -report events, the interview methods and focus collection the conversations could be used for the complementing and the data compilation apparatus. Not with standing, these boundaries, the present study has donated to the body of literature of study variables.

The consequence of this study cannot be simplified to the whole are Pakistan given that of the sample size. Moreover, this study has a number of limitations are there the research was conducted in limited area of Punjab, Pakistan, this study was based on a cross-sectional, Research could not use probability sampling due to lack of facilities the respondent could not be measure on important variable like marital Status etc.

The self-report measures were used, social class was not considered while recording responses. Questionnaire was used in Urdu/ English language, which may create some misunderstanding due to difficult terms. Even despite the fact that investigator tried her altitude paramount to be in command of all the exogenous variables other than a quantity of exogenous variables are extremely easier said than done to control like mood and psychological condition which may affect consequences of the study and the example of the study was self-selected by self. Prospect study is supposed for conducting in additional region in area of Pakistan in adding in somebody's company to Punjab to permit for additional universal termination and the applicability. It is also recommended to take account of additional incompletely construct-up neighborhood in the design procedure of principles based studies, predominantly in Pakistan. on the other hand, it will be practical to believe other than health check occupation, for demeanor outlook revise as they may present worth supplementary estimations which can lend a hand over the practitioners in going up their accessible sanatorium by combine their managerial approach.

It is additional recommended to judge other demographic aspect like income rate, background, belief and other feature to be aware of how nurses transversely pole away from each other groups perform towards an assortment of aspects of hospital. Consequently, in arrange to build a strong foundation and body of knowledge in this area in a Pakistani context; it would be practical to discover the matter from end to end the qualitative or varied method move toward. Study be capable of be also behavior on look after and managerial the academicians by have indepth meeting method, to move in the course of up by means of new representation in order to improve up this area of investigate additional.

This study is limited to Pakistan in order to draw conclusions that are generalized in Pakistan context as well as the other developing countries with the similar cultural practices. It is suggested that some other studies should be conducted where the effects of the work environment, organizational commitment and job burnout on the intention to quit should be implemented. In other words, other studies in Pakistan are recommended to use this model with a few changes. In addition to that, for future investigation, this model can also be tested 
empirically using data collected from other provinces in Pakistan or other countries that have unique and strong cultural practices.

This experiential study inspected for investigation the impact of between religious beliefs and impact of Covid-19 among the urban and rural citizens of Pakistan. The current study has main impartial was to determine the association among the religious beliefs and impact of COVID-19. Research design was based on correlation method, used in which data from the N340 defendants composed using a self-managed questionnaire from Pakistan.

Purposive sampling technique was used for respondents and data was examined a regression statically analysis. The result is explained in three forms: Demographic information, descriptive analysis, and inferential analysis. Finding shows that religious beliefs have significant negative correlation with the impact of COVID-19 and its dimensions. It is also shown that Table also shows that Impact of COVID-19 have significant correlation with its dimensions i.e., intrusion, avoidance and hyper arousal. Current study strengthens the above finding that strong religious beliefs have a positive role in a stressing event.

In context of Pakistan, the results of this study can explain following things. Due to strong Muslim religious beliefs, COVID-19 outbreak has little interference in the rural life. Although people are aware of the COVID-19 outbreak through Media yet have strong Muslim religious beliefs. They have overcome their fear of the pandemic. Due to strong Muslim religious beliefs, they believe that Covid-19, a disease is brought by the Almighty God, and it is the Almighty who can remove this pandemic. It was seen that Pakistani rural population are less hyperactive aroused about COVID-19 due to their strong religious beliefs.

Few recommendations areas per findings of this study, an individual who has strong religious beliefs and face the COVID-19epidemic, he or she considers that this pandemic is from the Almighty and we can alleviate it through prayers to God and strengthening the belief in God. Strong Religious Beliefs help to counter the fear of COVID-19 which is produced throughout the world and hence they show less bodily reactions. Although COVID-19 doesn't leave any person, either believer or non-believer, Government should keep in mind the religious factor in the outbreak of COVID-19.

More research is required to ascertain those religious beliefs are helping the outbreak of COVID-19or restricting it. Further studies are suggested to replicate the finding in other religions than the Islam. The willingness of emergency psychological management services including religious therapies, mental health services, and the local community appointments at Punjab (Pak) Level machinery for ensuring the capacity to right away launch the restraint activities in response to any recovery if the in cases of COVID-19 appear. It should be the Prioritize of the immediate testing and separation, exhaustive case, particular contact tracing and the rigorous quarantine center as the non-effected people may also suffered from physiological and mental disorder as well.

The general public should be given religious based education for take serious safeties measurement to meet of COVID-19 as the travelling, myths; remorse of people is major reason. Rapidly manage plans in light of the psychological services for new knowledge on the 
effectiveness of mental health measures against COVID-19. There is need to do more research in different Provinces of Pakistan.

\section{References}

Altamirano, M. A., \& Collazo, C. E. R. (2020). Leading with emotional intelligence: How leaders of a diverse-based urban college in new york successfully respond to the COVID-19 crisis of 2020. Journal of Education, Innovation, and Communication, (Special Issue), 65-75.

Bisri, H. (2020). Religious community responses to COVID-19: Case study on Muslim small community. International Journal of Psychosocial Rehabilitation, 24(8), 10439-10446.

Dam, P., Mandal, S., Mondal, R., Sadat, A., Chowdhury, S. R., \& Mandal, A. K. (2020). COVID19: Impact on transport and mental health. Journal of Transport $\Xi^{\circ}$ Health, 19, 100969.

Gearhart, R. M. (2017). The Perceptions and Fears of Vaccines in Rural Pennsylvania (Doctoral dissertation, Indiana University of Pennsylvania).

Giberson, K. W. (2012). The wonder of the universe: hints of God in our fine-tuned world. InterVarsity Press.

Kagan, A., Black, S. E., Duchan, J. F., Simmons-Mackie, N., \& Square, P. (2001). Training volunteers as conversation partners using" Supported Conversation for Adults With Aphasia"(SCA).

Kor, Y. Y. (2006). Direct and interaction effects of top management team and board compositions on R\&D investment strategy. Strategic management journal, 27(11), 1081-1099.

Laires, P. A., Dias, S., Gama, A., Moniz, M., Pedro, A. R., Soares, P., ... \& Nunes, C. (2021). The association between chronic disease and serious COVID-19 outcomes and its influence on risk perception: survey study and database analysis. JMIR Public Health and Surveillance, 7(1), e22794.

Mackenzie, E. R., Rajagopal, D. E., Meilbohm, M., \&Lavizzo-Mourey, R. (2000). Spiritual support and psychological well-being: Older adults' perceptions of the religion and health connection. Alternative Therapies in Health and Medicine, 6(6), 37-48.

Mannan, N., \&Akram, A. (2020). Variation of Clinical Features of Covid 19 Patients. Bangladesh Journal of Infectious Diseases, S54-S57.

Maselko, J., \&Kubzansky, L. D. (2006). Gender differences in religious practices, spiritual experiences and health: Results from the US General Social Survey. Social Science \& Medicine, 62(11), 2848-2860.

Moreira-Almeida, A., Lotufo Neto, F., \& Koenig, H. G. (2006). Religiousness and mental health: a review. Brazilian Journal of Psychiatry, 28(2), 242-250.

Murenje, M., \& Porter, S. K. (2020). Covid-19: challenges and prospects for the social work profession. International Federation of Social Workers Press. Retrieved July 26, 2020.

Panek, R. (2019). The Trouble with Gravity: Solving the Mystery Beneath Our Feet. Houghton Mifflin.

Razak, A. M. I., \& Saleem, A. M. (2021). COVID-19: The Crossroads for Sinhala-Muslim Relations in Sri Lanka. Journal of Asian and African Studies, 1-14. 
Sharma, S., Suvalka, C., Joshi, M., \& Bahuguna, A. (2021). Potential inhibitors and plant-based technology: An alternative approach to treat corona virus. Bioorganic Chemistry, 117, 105460 .

Usher, K., Durkin, J., \& Bhullar, N. (2020). The COVID-19 pandemic and mental health impacts. International Journal of Mental Health Nursing, 29(3), 315-318.

Wells, S. (2015). Preface: Why Shakespeare? Shakespeare and Stratford-upon-Avon; Theatre in Shakespeare's time; Shakespeare in London; Plays of the 1590s; Shakespeare and comic form; Return to tragedy; The classical plays; Tragicomedy; Epilogue; Chronology: Shakespeare's works; Further reading; Index (Vol. 60). Oxford University Press, USA. 